\title{
Adequação das rotulagens alimentícias frente à legislação vigente
}

\section{Suitability of labelling edible front of the law governing}

\author{
1 Aline Cristina Teixeira Mallet alinectmallet@gmail.com \\ 2 Rhuan Victor de Albuquerque de Oliveira \\ 3 Cyntia Ferreira de Oliveira \\ 3 Margareth Lopes Galvão Saron \\ 4 Lívia Martinez Abreu Soares Costa
}

\footnotetext{
Centro Universitário de Volta Redonda - UniFOA / Centro Universitario de Barra Mansa - UBM

Egresso do Centro Universitário de Volta Redonda - UniFOA

Docente do Centro Universitário de Volta Redonda - UniFOA

4 Pós doutoranda da Universidade Federal de Lavras - UFLA
}

\section{Resumo}

A enorme busca de informações nutricionais confiáveis gera a necessidade de legislações vigentes que regulamentem o setor alimentício no âmbito da qualidade, segurança e disponibilidade do alimento. A garantia de informações úteis e confiáveis é um direito assegurado ao consumidor, o que colabora com uma melhor escolha de produtos. Todavia, o cumprimento dessas legislações, muitas vezes, não tem sido inspecionado. 0 presente trabalho teve como objetivo verificar a conformidade da rotulagem de produtos alimentícios comercializados frente à legislação brasileira em vigor. Trata-se de um estudo observacional e descritivo, realizado na Região Sul Fluminense - RJ, onde a coleta de dados ocorreu entre o período de janeiro a agosto de 2015. Dos 76 rótulos analisados, $96 \%$ apresentaram, no mínimo, uma inadequação frente à legislação vigente e, apenas $4 \%$ dos rótulos estavam plenamente de acordo com o estabelecido na legislação. 0 item que apresentou maior número de inadequações foi o que diz respeito à expressão "traços de leite", enquanto o prazo de validade foi o item avaliado que obteve menor índice de inadequações. Conclui-se que a maioria dos estabelecimentos e dos rótulos analisados não atendeu integralmente aos requisitos de rotulagem exigidos pelas legislações em questão. As informações presentes nas embalagens estudadas foram, em grande parte, deficientes ou mesmo errôneas, dificultando o bom entendimento acerca dos produtos pelos consumidores.

\section{Palavras-chave}

Rotulagem nutricional. Alimento. Legislação sanitária. Legislação vigente. Consumidor.

\begin{abstract}
The huge search for reliable nutritional labeling generates the need of current legislations that regulate the food industry regarding quality, safety and food availability. The assurance of useful and reliable information is a guaranteed rightfor the consumer, which contributes to a better selection of products. However, the accomplishment of these legislations is usually not inspected. The aim of this research is to verify the conformity of commercialized food labeling, regarding expiration date, production, origin, shipment, customer service, ingredients, gluten, traces of milk, according to the current Brazilian legislation. It is an observative and descriptive study, accomplished in the South Fluminense Region - RJ, the collection of data occurred during the period of January until August, 2015. From the 76 analyzed labels, 96\% presented, at least, one inadequacy according to the current legislation and only $4 \%$ were completely in accordance with the established by the legislation. The item that presented the biggest number of inadequacies was the one regarding traces of milk. Although, the expiration date item was the one that obtained the smallest number of inadequacies. As a result, the majority of establishments and labels that were analyzed didn't reach integrally all the labeling requisites imposed by the legislations in question. Most of the collected information contained on the labels was inaccurate or erroneous, making it difficult for the consumer to understand its contents.
\end{abstract}

\section{Keywords}

Nutritional labeling. Food. Sanitary legislation. Current legislation. Consumer.

\section{Como você deve citar?}

MALLET, Aline Cristina Teixeira et al. Adequação das rotulagens alimentícias frente à legislação vigente. Cadernos UniFOA, Volta Redonda, n. 35, p. 101-110, dez. 2017. 
Adequação das rotulagens alimentícias

frente à legislação vigente

\section{INTRODUÇÃO}

Rotulagem Nutricional é toda descrição designada ao consumidor, a fim de informar, não só as propriedades nutricionais do alimento a ser consumido, como também as datas de validade e fabricação, a origem, o serviço de atendimento ao consumidor (SAC), o lote, os ingredientes utilizados para o preparo do produto, presença de glúten e traços de leite. A mesma descrição se aplica a todos os alimentos produzidos, embalados e comercializados na ausência do consumidor (BRASIL, 2002; BRASIL, 2003).

De acordo com Agência Nacional de Vigilância Sanitária (ANVISA), órgão diretamente ligado ao Ministério da Saúde, responsável em fiscalizar a produção, comercialização e rotulagem dos alimentos, a busca constante e crescente de informações confiáveis por parte da população exige do Governo e do setor produtivo a inclusão de uma eficaz rotulagem nutricional de alimentos, já que essas informações facilitam o consumidor a conhecer as propriedades nutricionais dos produtos, contribuindo para o consumo adequado, podendo ainda exercer um papel proveitoso como meio de prevenção de agravos à saúde (BRASIL, 2003).

Entretanto, Valente (2002 apud Câmara et al., 2008) registra que o acesso à informação correta sobre o conteúdo dos alimentos, por ser um elemento que impacta na adoção de práticas alimentares e estilos de vida saudáveis, configura-se, em seu conjunto, numa questão de segurança alimentar e nutricional.

Segundo a Conferência Nacional de Segurança Alimentar e Nutricional (CONSEA), a Segurança Alimentar implica que a maneira como o alimento é produzido, comercializado e consumido estão completamente interligados. A grande importância desse fato leva em conta três aspectos fundamentais: quantidade, acesso constante e a qualidade dos alimentos. Assim, o alimento disponibilizado para o consumo não pode estar sob risco de qualquer tipo de contaminação microbiológica, problemas de decomposição e outros decorrentes de prazos de validade vencidos (CONSEA, 2004).

Dentro desse âmbito, compete ao Estado fiscalizar o cumprimento da legislação de alimentos, enquanto é de responsabilidade da indústria e do estabelecimento distribuidor rotular alimentos com as informações para a educação do consumidor (WHO, 1996).

No sentido de querer contribuir para o debate sobre o uso de informativos das rotulagens nutricionais, este estudo teve como objetivo avaliar a adequação dos rótulos nutricionais.

\section{MATERIAIS E MÉTODOS}

Trata-se de um estudo observacional e descritivo dos informativos referentes às propriedades nutricionais do alimento, bem como as datas de validade e fabricação, a origem, o serviço de atendimento ao consumidor (SAC), o lote, os ingredientes utilizados para o preparo, presença de glúten e traços de leite, declarados obrigatoriamente nos rótulos das embalagens.

As amostras foram compostas por alimentos embalados na ausência do consumidor e comercializados na Região Sul Fluminense (RJ).

Foram avaliados rótulos de alimentos produzidos por 45 estabelecimentos comerciais, como, por exemplo, padaria, mercearias, cafeterias, entre outros, em um total de 76 amostras, no período de janeiro a agosto de 2015. 
Aline Cristina Teixeira Mallet / Rhuan Victor de Albuquerque de Oliveira Cyntia Ferreira de Oliveira I Margareth Lopes Galvão Saron I Lívia Martinez Abreu Soares Costa

Os critérios de inclusão foram estabelecimentos comerciais, como supermercados, lanchonetes, padarias, cafeterias e restaurantes que comercializavam alimentos com informativos sobre rotulagem nutricional.

Para verificação das conformidades e não conformidades dos rótulos, foram utilizadas as seguintes legislações em vigor pertinentes aos itens analisados: Resolução RDC ANVISA/MS n 26, de 02 de julho de 2015 (Rotulagem de Alimentos Alergênicos); Resolução RDC ANVISA/MS nº 40, de 08 de fevereiro de 2002 (Regulamento técnico para rotulagem de alimentos e bebidas embalados que contenham glúten); Resolução RDC ANVISA/MS n 163, de 17 de agosto de 2006 (Rotulagem Nutricional Obrigatória de Alimentos e Bebidas Embalados); Resolução RDC ANVISA/MS n 259, de 20 de setembro de 2002 (Regulamento Técnico sobre Rotulagem de Alimentos Embalados); Resolução RDC ANVISA/MS $n^{\circ} 360$, de 23 de dezembro de 2003 (Regulamento Técnico sobre Rotulagem Nutricional de Alimentos Embalados, tornando obrigatória a rotulagem nutricional).

Além das legislações citadas, foram utilizadas a legislação do Ministério da Justiça - Lei 8.078, de 11 de setembro de 1990 (Código de Defesa do Consumidor) e legislação do Ministério da Saúde - Lei n. 10.674, de 16 de maio de 2003 (Obriga a que todos os produtos alimentícios comercializados informem sobre a presença de glúten, como medida preventiva e de controle da doença celíaca).

No momento da coleta de dados, foi verificado se, no estabelecimento, havia a presença de um profissional nutricionista responsável técnico pelo setor de produção.

As análises das adequações de ingestão foram expressas em porcentagem, utilizando-se o programa computacional Microsoft Excel 2010.

\section{RESULTADOS E DISCUSSÃO}

Nas amostras dos rótulos, foram analisados componentes como data de validade e de fabricação, identificação da origem, o serviço de atendimento ao consumidor (SAC), identificação do lote, os ingredientes usados para o preparo do produto, glúten e traços de leite.

Dos 45 locais avaliados, 44 locais apresentaram, no mínimo, uma rotulagem com algum tipo de não concordância com a legislação vigente, o que corresponde a $98 \%$ dos estabelecimentos visitados. Apenas um dos locais (2\%) estava com todas as rotulagens inteiramente de acordo com o preconizado (Figura 1).

A Figura 1 apresenta os resultados de conformidade e não conformidade dos estabelecimentos quanto à rotulagem. 
Figura1 - Representação gráfica da adequação/inadequação da rotulagem nos estabelecimentos.

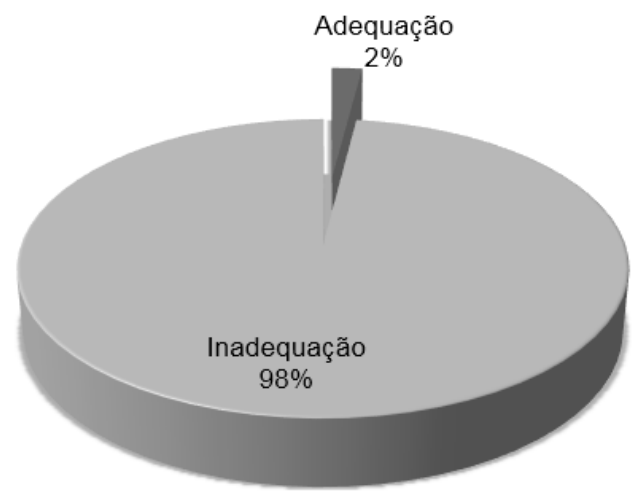

Fonte: dos autores.

Esse valor elevado (98\%) pode ser decorrente, principalmente, da ausência de um profissional Nutricionista nos estabelecimentos comerciais visitados. Destes, apenas dois (02) possuíam orientação profissional de um nutricionista, entretanto, em um (01), ainda foram constatadas irregularidades em relação à rotulagem.

A Figura 2 representa o percentual de irregularidades encontradas em cada amostra.

Figura 2 - Porcentagem das amostras inadequadas.

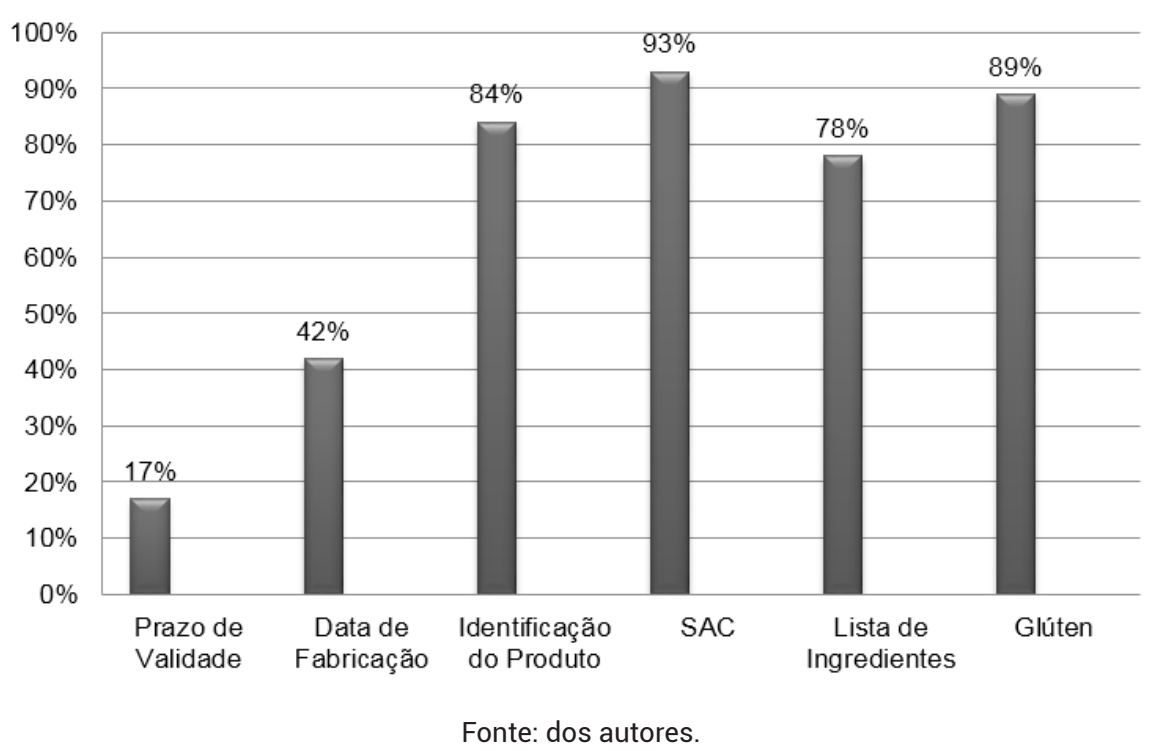

Cada item será discutido mais detalhadamente abaixo, a fım de salientar a importância da presença desses dados nas rotulagens alimentícias, para a prevenção e integridade da saúde do consumidor. 
Aline Cristina Teixeira Mallet / Rhuan Victor de Albuquerque de Oliveira Cyntia Ferreira de Oliveira I Margareth Lopes Galvão Saron I Lívia Martinez Abreu Soares Costa

\subsection{Serviço de atendimento ao consumidor}

O SAC é um elemento estratégico, uma vez que aplica as funções de inovador, transformando riscos e ameaças em ações proativas. Funciona como radar para a empresa, captando informações do mercado e complementando-se por intermédio de pesquisas. Funciona também como agente de mudanças, provocando mudanças internas na organização e como auditor, quando atua no controle de serviços (CRUZ, 2005).

A Lei 8.078, de 11 de setembro de 1990, conhecida como Código de Defesa do Consumidor (CDC), dita como obrigatória a inscrição do número do SAC, de forma clara e objetiva (BRASIL, 2013).

Consequentemente, a alta porcentagem de inadequação referente a esse item (93\%) é tida como infratora, uma vez que essa situação coíbe o consumidor ao acesso às informações referentes ao estabelecimento responsável pela distribuição do produto e informações inscritas nas rotulagens, além de impedir o rastreamento do produto.

Para permanecerem no mercado, portanto, as empresas precisam investir em mecanismos de interatividade com os consumidores, de forma a, no mínimo, igualar a concorrência, e a evitar pressões dos órgãos de defesa do consumidor.

\subsection{Identificação do produto}

A Resolução RDC ANVISA/MS n 259, de 20 de setembro de 2002, trata como obrigatória a identificação tanto de lote quanto de origem. 0 item origem deve indicar no rótulo nome (razão social) do fabricante, endereço completo, número de registro ou código de identificação do estabelecimento fabricante junto ao órgão competente. Enquanto para indicação do lote pode ser utilizado um código-chave precedido pela letra "L" e a data de fabricação/validade, sempre que indicar, pelo menos, o dia e o mês, ou o mês e o ano (BRASIL, 2002).

Essa informação, de suma importância para a identificação e rastreamento do produto, possibilita a intervenção adequada por parte de órgãos, como, por exemplo, as vigilâncias sanitárias (RIBEIRO, 2012).

A grande porcentagem dessas inadequações (média de 84\%) com informações incompletas, ausentes ou ilegíveis caracterizam fraude ou desconhecimento por parte dos produtores, frente ao CDC.

\subsection{Lista de ingredientes}

A Resolução RDC ANVISA/MS n 259, de 20 de setembro de 2002, dita como informação obrigatória, para a rotulagem de alimentos embalados, a lista de ingredientes (BRASIL, 2002). Apresenta informações essenciais sobre a composição do produto adquirido e deve ser utilizado como base para o consumidor identificar quais alimentos estão presentes no produto (BENDINO, 2012). No entanto, o consumidor, em geral, apresenta dificuldades em adquirir o hábito de leitura, associado à incompreensão da linguagem técnica usada nos rótulos, faz com que o entendimento possa ser alcançado somente por um público mais esclarecido (MARINS, 2008).

Além disso, essa Resolução abrange os aditivos alimentares, informando que eles devem ser declarados como parte da lista de ingredientes (BRASIL, 2002). 
Sendo assim, uma vez que a porcentagem das inadequações referente à lista de ingredientes é de $78 \%$, a expressão que diz respeito ao uso de aditivos alimentares no preparo do alimento é do mesmo percentual.

De acordo com Evangelista (2000), o incorreto emprego dos aditivos em situações diversas, como, por exemplo, quando nos produtos há ausência dos aditivos mencionados na rotulagem ou a presença deles, sem também constarem no rótulo, está relacionado a reações adversas, tais como excitação/irritação da mucosa gastrointestinal, desencadeamento de reações alérgicas e, potencialmente, a carcinogenicidade.

Adicionalmente, Wood (2002 apud Marins et al., 2008), afirmam que é intolerável que esses aditivos alimentares não estejam devidamente expressos nos rótulos das embalagens alimentícias pelas indústrias produtoras de alimentos.

\subsection{Data de fabricação}

A porcentagem de inadequações referente à data de fabricação foi de $42 \%$. Porém, segundo a Resolução RDC $n^{\circ} 259$, de 20 de setembro de 2002, apenas a menção da lista de ingredientes, origem, lote e prazo de validade é tida como obrigatória, sendo, portanto, esse item facultativo ao produtor.

Entretanto, uma vez que, para a identificação do lote, pode ser utilizada a data de fabricação, pode-se comprometer o rastreamento e o recolhimento do produto, em caso de problemas de contaminação, por exemplo.

\subsection{Prazo de validade}

O item que apresentou menor número de não conformidades foi o prazo de validade (17\%). Entretanto, do percentual de amostras adequadas, $6 \%$ encontravam-se com o prazo de validade expirado (Figura 3).

Figura 3 - Percentual dos prazos de validade vencidos comparado à quantidade de amostras que expressam o prazo de validade.

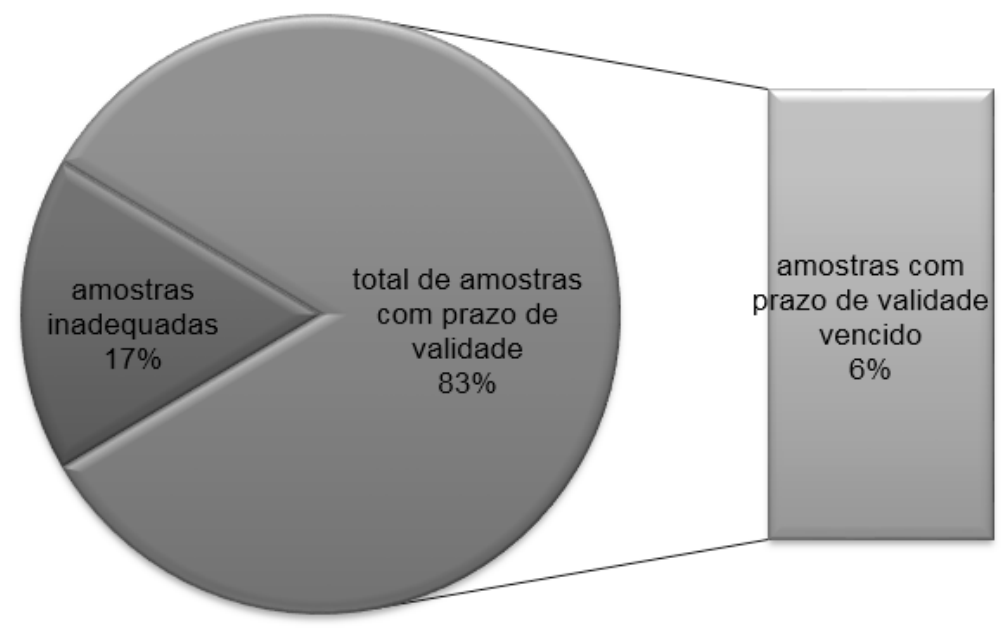

Fonte: dos autores. 
Aline Cristina Teixeira Mallet / Rhuan Victor de Albuquerque de Oliveira Cyntia Ferreira de Oliveira I Margareth Lopes Galvão Saron I Lívia Martinez Abreu Soares Costa

O Código de Defesa do Consumidor (CDC) regulamenta que são impróprios para o consumo todos os alimentos que estejam com o prazo de validade vencido, e serão consideradas como práticas infrativas a oferta de produtos sem a informação do prazo de validade (BRASIL, 2013).

Segundo um estudo de Bendino et al. (2012), o prazo de validade é uma das informações mais buscadas pelos consumidores, exemplificando, dessa forma, a alta porcentagem de adequações do produto e a importância da expressão nos rótulos alimentícios. 0 consumidor associa a qualidade do alimento com a validade, pois adquirir um produto vencido acarretaria prejuízo tanto financeiro quanto para a saúde.

Diante do que foi exposto, pode-se observar que há falhas no órgão responsável pela fiscalização dessas diretrizes, colocando em risco a saúde do consumidor.

A realização periódica de estudos que, assim como este, visam problematizar a adequação das rotulagens frente à legislação vigente pode tornar mínimos os problemas de ordem tanto sanitária quanto relacionada às questões legislativas (DOGO, 2013).

\subsection{Presença de traços de leite e Glúten}

Segundo a Resolução RDC ANVISA/MS n² 26, de 02 de julho de 2015, que trata dos requisitos para rotulagem obrigatória dos alimentos causadores de alergias alimentares, todos os rótulos deverão informar a existência de 17 alimentos, entre eles, o leite de todos os mamíferos. (BRASIL, 2015).

Esse informativo expresso no rótulo auxilia na prevenção e no controle de alguns grupos de riscos. Sendo assim, é preciso uma fiscalização mais rígida, a fim de inspecionar a adequação na nova Resolução.

Como medida preventiva e de controle da doença celíaca, a Lei n 10.674 , de 16 de maio de 2003 , e a RDC n 40, de 08 de fevereiro de 2002, tornou obrigatória as inscrições "CONTÉM GLÚTEN" ou "NÃO CONTÉM GLÚTEN" em caracteres nítidos e de fácil leitura nos rótulos de alimentos comercializados (BRASIL, 2002; BRASIL, 2003). Posto isto, 89\% das rotulagens estão em inconformidade com a legislação.

Segundo Picolotto (2002 apud Câmara et al., 2008), a inadequação da rotulagem nutricional da expressão "CONTÉM GLÚTEN" ou "NÃO CONTÉM GLÚTEN" é grave, uma vez que a presença do glúten é prejudicial para consumidores que possuem a doença celíaca.

De acordo com Ciclitira e Moodie (2003 apud Ribeiro et al., 2012), a única terapia nutricional para essa patologia é a restrição total de alimentos que contenham glúten. Sendo assim, é importante intensificar a questão da confiabilidade das informações que se relacionam diretamente à segurança dos alimentos, criando um elo entre o consumidor, o alimento e o produtor. Portanto, o acesso a essas informações corretas é de suma importância para a prevenção do risco de alergias alimentares.

É elevada a prevalência de produtos que não seguem as normas de rotulagem (89\%), concluindo que é indispensável maior rigidez da ANVISA, sobretudo no caso desse item. De tal modo, as amostras que não indicarem esse item nas rotulagens alimentícias, além de estar em desacordo com a legislação, omitem informações ao consumidor. 


\section{CONCLUSÃO}

Este estudo permitiu avaliar e identificar dados de inadequações de rotulagens alimentícias frente à legislação vigente.

Sendo as rotulagens responsáveis pela informação do produto ao consumidor, permitem escoIhas alimentares mais saudáveis. Dessa forma, conclui-se que a maioria dos estabelecimentos e dos rótulos analisados não atendeu integralmente aos requisitos de rotulagem exigidos pelas legislações em questão. As informações presentes nas embalagens estudadas foram, em grande parte, deficientes ou mesmo errôneas, dificultando o bom entendimento acerca dos produtos pelos consumidores.

A pouca fiscalização do órgão responsável, vinculada à falta de um profissional Nutricionista capacitado voltado somente para o planejamento de rotulagens alimentícias, é tida como fator determinante no resultado encontrado.

Necessita-se, portanto, de vigilância permanente, a fim de se garantir e ofertar alimentos dentro das normas sanitárias, respeitando-se o direito do consumidor às escolhas saudáveis. 
Aline Cristina Teixeira Mallet / Rhuan Victor de Albuquerque de Oliveira Cyntia Ferreira de Oliveira I Margareth Lopes Galvão Saron I Lívia Martinez Abreu Soares Costa

\section{REFERÊNCIAS}

AGÊNCIA NACIONAL DE VIGILÂNCIA SANITÁRIA. Resolução RDCANVISA/MS nº 26, de 02 de julho de 2015. Rotulagem de Alimentos Alergênicos. Ministério da Saúde - MS. Agência Nacional de Vigilância Sanitária.

AGÊNCIA NACIONAL DE VIGILÂNCIA SANITÁRIA - ANVISA. Resolução RDC $\mathbf{n}^{\circ}$ 40, de 08 de fevereiro de 2002. Aprova o Regulamento técnico para rotulagem de alimentos e bebidas embalados que contenham glúten. Ministério da Saúde - MS. Agência Nacional de Vigilância Sanitária. Diário Oficial da União. n 29, de 13 de fevereiro de 2002.

AGÊNCIA NACIONAL DE VIGILÂNCIA SANITÁRIA - ANVISA. Resolução RDC $\mathbf{n}^{\circ}$ 163, de 17 de agosto de 2006. Rotulagem Nutricional Obrigatória de Alimentos e Bebidas Embalados. Ministério da Saúde - MS. Agência Nacional de Vigilância Sanitária.

AGÊNCIA NACIONAL DE VIGILÂNCIA SANITÁRIA - ANVISA. Resolução RDC n² 259, de 20 de setembro de 2002. Aprova o Regulamento Técnico sobre Rotulagem de Alimentos Embalados. Ministério da Saúde - MS. Agência Nacional de Vigilância Sanitária. Diário Oficial da União. nº 251, de 26 de dezembro de 2003.

AGÊNCIA NACIONAL DE VIGILÂNCIA SANITÁRIA - ANVISA. Resolução - RDC n. ${ }^{\circ} \mathbf{3 6 0}$, de 23 de dezembro de 2003. Aprova o Regulamento Técnico sobre Rotulagem Nutricional de Alimentos Embalados, tornando obrigatória a rotulagem nutricional. Ministério da Saúde - MS. Agência Nacional de Vigilância Sanitária. Diário Oficial da União n 251, de 26 de dezembro de 2003.

BRASIL. Código de Proteção e Defesa do Consumidor (1990). Código de proteção e defesa do consumidor e legislação correlata. 5. ed. - Brasília: Senado Federal, Subsecretaria de Edições Técnicas, 2012. 106 p.

BRASIL. Lei 10.064, de 16 de maio de 2003. Obriga a que os produtos alimentícios comercializados informem sobre a presença de glúten, como medida preventiva e de controle da doença celíaca. Disponível em: <http://www.planalto.gov.br/ccivil_03/leis/2003//10.674.htm>. Acesso em: 15 jan. 2017

BENDINO, N. I.; POPOLIM, W. D.; OLIVEIRA, C. R. A. Avaliação do conhecimento e dificuldades de consumidores frequentadores de supermercado convencional em relação à rotulagem de alimentos $\mathrm{e}$ informação nutricional. J Health Scilnst, v. 30, n. 3, p. 261-5, 2012.

CÂMARA, M. C. C.; et al. produção acadêmica sobre a rotulagem de alimentos no Brasil. Rev Panam Salud Publica, v. 23, n. 1, p. 52-8, 2008.

CONSEA. Documento de Referência da II Conferência Nacional de Segurança Alimentar e Nutricional. Brasília: CONSEA: 2004.

CRUZ, A. M. O; et al. O serviço de atendimento ao cliente (SAC): um instrumento de gestão ou uma mera formalidade para cumprir exigências legais? XXV Encontro Nac. de Eng. de Produção - Porto Alegre, outubro/novembro, 2005.

DA CUNHA, L.R.; et al. Desenvolvimento e avaliação de embalagem ativa com incorporação de lactase.

Ciênc. Tecnol. Aliment., v. 27, 2007. 
DOGO, L. A. et al. Ocorrência de produtos fora da validade em gôndolas de hipermercados da grande São Paulo - SP. Saúde em Foco, n. 7, p: 35-40, 2013.

EVANGELISTA, J. Definição e normas regulamentares. In: Evangelista J, organizador. Tecnologia de alimentos. 2. Ed. São Paulo: Editora Atheneu; 2000. p.433-450.

MARINS, B. R.;JACOB, S. C.; PERES, F. Avaliação qualitativa do hábito de leitura e entendimento: recepção das informações de produtos alimentícios. CiêncTecnolAliment, v. 28, n. 3, p. 579-85, 2008.

RIBEIRO, R. O. R. et al. Avaliação da adequação da rotulagem de geleias reais. Revista Brasileira de Ciência Veterinária, v. 19, n. 2, [s/p.], 2012.

WORLD HEALTH ORGANIZATION - WHO. Division of Food and Nutrition. Guidelines for strengthening a National Food Safety Programme. Geneve, 1996. 